\title{
TIME, INFINITY, AND THE CREATION OF THE UNIVERSE: A STUDY IN AL-KINDI'S FIRST PHILOSOPHY
}

\author{
Richard B. Davis \\ University of Toronto
}

I.

Widely acclaimed as the first genuine philosopher in the Islamic Tradition, ${ }^{1}$ Abu Yusuf Ya'qub b. Ishaq al-Kindi (c.801-c.873) is a significant figure in the history of natural theology, having formulated what is perhaps the earliest statement of the argument for God's existence based on the creation of the universe ex nihilo. ${ }^{2}$ Deeply committed to the doctrine of creation found in the Qur'an, al-Kindi rejected the Aristotelian belief in the eternity of the universe and matter; accordingly, he attempted to demonstrate philosophically that the universe began to exist a finite time ago, and therefore that there must have been a Creator who brought the universe into being out of nothing. For al-Kindi, the temporal origination of the universe strictly implies the creation of the universe. 3

\footnotetext{
I See, for example, the statements to this effect in William Craig, The Cosmological Argument from Plato to Leibniz (London: Macmillan, 1980), p. 61; Ahmed Fouad El-Ehwany, "AlKindi," in A History of Muslim Philosophy, ed. M. M. Sharif (Wiesbaden: Otto Harrassowitz, 1963), p. 429; Majid Fakhry, A History of Islamic Philosophy, 2nd ed. (New York: Columbia University Press, 1983), p. 66; Kevin Staley, "Al-Kindi on Creation: Aristotle's Challenge to Islam," Journal of the History of Ideas 50 (1989): 355.

2 See Majid Fakhry, "The Classical Islamic Arguments for the Existence of God," Muslim World 47 (1957): 140. According to George Atiyeh, the argument from creation is the "most important argument for God's existence in the philosophy of al-Kindi" (George N. Atiyeh, Al-Kindi: The Philosopher of the Arabs [Rawalpindi: Islamic Research Institute, 1966], p. 49).
}

3 The term 'ibda' is employed by al-Kindi to designate the temporal creation of the universe ex nihilo. Although 'ibda' does not have this meaning in the Qur'an, and although later philosophers used this term to refer to a kind of Neoplatonic 'eternal creation', nevertheless "there can be no doubt that al-Kindi ... gave to 'ibda' this meaning of a temporal creation from nothing" (Richard Walzer, "New Studies on Al-Kindi," in Richard Walzer, Greek into Arabic: Essays on Islamic Philosophy, Oriental Studies [Oxford: Bruno Cassier, 1962], p. 189). 
Thus, al-Kindi's doctrine of creation turns on whether or not it can be demonstrated that the universe had a beginning in time. The most complete treatment of this question is found in al-Kindi's treatise On First Philosophy. ${ }^{4}$ There he advances three arguments in favour of the temporal origination of the universe. In this paper, I shall be concerned only with the first of these, namely, the argument based on the necessary concomitance of body, motion, and time. I shall argue that it does not appear to successfully establish that the universe began to exist in tempore. In the course of discussion, however, it will become clear that I am not persuaded that recent set theoretic criticisms of this argument are cogent. My conclusion, nevertheless, will be that one is not rationally justified in inferring that the universe was created by God ex nihilo in the finite past on the basis of this argument.

\section{II.}

Al-Kindi begins his discussion in On First Philosophy by laying out six principles which he considers "true first premises." 5 They are, says al-

4 Ya 'qub ibn Ishaq al-Kindi, Al-Kindi's Metaphysics: A Translation of Ya' qub ibn Ishaq alKindi's Treatise 'On First Philosophy', with an Introduction and Commentary by Alfred L. Ivry (Albany, N.Y.: State University of New York Press, 1974), pp. 67-75. For arguments similar to these see al-Kindi's related epistles translated in N. Rescher and $\mathrm{H}$. Khatchadourian, "Al-Kindi's Epistle on the Finitude of the Universe," Isis 57 (1966): 426-433; F.A. Shamsi, "Al-Kindi's Epistle on What Cannot Be Infinite and of What Infinity May Be Attributed," Islamic Studies 14 (1975): 123-144.

5 Al-Kindi, in "On First Philosophy," 114.13, p. 68. Although al-Kindi does not explicitly defend these principles in On First Philosophy, proofs for the truth of principles (1), (4), and (5) may be found in his epistle "On The Explanation of the Finitude of the Universe." See Rescher, op. cit., pp. 429-431. Ivry contends that these principles are proved "in circular fashion" (Alfred Ivry, "Commentary to 'On First Philosophy'," in Al-Kindi's Metaphysics: A Translation of Ya' 'qub ibn Ishaq al-Kindi's Treatise 'On First Philosophy' [Albany, N.Y.: State University of New York Press, 1974], p. 147). I think Ivry is correct. For example, alKindi's proof for the first principle can be set out as follows:

(i)

(iii)

(iv)

(v)

(vi)

(vii)

(viii)

(ix)

(x)

$$
\sim[(\mathrm{A}>\mathrm{B}) \text { v }(\mathrm{B}>\mathrm{A})]
$$$$
\sim(\mathrm{A}>\mathrm{B}) \& \sim(\mathrm{B}>\mathrm{A})
$$$$
A \neq B
$$$$
(\mathrm{A} \neq \mathrm{B}) \supset[(\mathrm{A}>\mathrm{B}) \vee(\mathrm{B}>\mathrm{A})]
$$$$
(\mathrm{A}>\mathrm{B}) \text { v }(\mathrm{B}>\mathrm{A})
$$$$
\sim(\mathrm{B}>\mathrm{A})
$$

$\mathrm{A}>\mathrm{B}$

$\sim(\mathrm{A}>\mathrm{B})$

$\mathrm{A}=\mathrm{B}$

$\sim[(\mathrm{A}>\mathrm{B}) \vee(\mathrm{B}>\mathrm{A})] \supset(\mathrm{A}=\mathrm{B})$
Asp for CP

(i) DM

Asp for RAA

Premise

(iii), (iv) MP

(ii) Simp

(v), (vi) DS

(ii) Simp

(iii)-(ix) RAA

(i)-(ix) $\mathrm{CP}$ 
Kindi's modern-day commentator Alfred Ivry, "thought with no mediation," that is, "as intellectual intuitions, free of prior logical, as well as physical, mediation." 6 Letting "> stand for "is greater than", "<' for "is smaller than", and '=' for "is equal to", Al-Kindi's six self-evident first principles can be conveniently summarized as follows:

(1) For any bodies $A$ and $B$, if it is not the case that either $(A>B)$ or $(B>A)$, then $A=B$.

(2) For any bodies $A$ and $B$, if $A=B$, then the dimensions between the limits of $A$ and the dimensions between the limits of $B$ are equal in potentiality and actuality.

(3) Finite $=d f$ not infinite.

(4) For any bodies $A, B$, and $C$, if $A=B$ and $C$ is added to $\mathrm{B}$, then $\mathrm{BC}>\mathrm{B}$, and therefore $\mathrm{BC}>\mathrm{A}$ (where $\mathrm{BC}$ is the body resulting from the addition of $B \& C$ ).

(5) For any bodies $A$ and $B$, if $A$ and $B$ are finite, then if $A$ and $B$ are joined, the resultant body $A B$ will be of finite magnitude.

(6) If A and B are generically related things - that is, things falling under a single genus (e.g., the genus of magnitude) - then if $A<B$, then either $A$ is inferior to $B$ or a portion (part, segment) of $B$.

A word of explanation should be said concerning the terms used in these principles. With regard to the term 'body', it seems clear that al-Kindi here employs 'body' to denote this or that body; that is, certain particular bodies, primary substances in the Aristotelian sense. ${ }^{7}$ This is borne out by the fact

(Here ' $A$ ' and ' $B$ ' stand for particular bodies, and ' $>$ ' represents the 'greater than' relation.) It will be noticed that the conclusion - i.e., (x) - appears in transposed form in step (iv); the argument is circular. But this does not mean that is question-begging, any more than the Law of Non-Contradiction is question-begging because at some point in any argument for its truth that very law will be invoked.

6 Ibid.

${ }^{7}$ Recall that for Aristotle a primary substance is that 'which is neither asserted of a subject nor present in a subject' (e.g., this man or this horse). See Aristotle, Categories, 2.a. 12-15. We must be careful to point out, however, that al-Kindi also uses 'body' to refer to the genus of body, one of the various genera falling under the single genus of magnitude. ".... the genus of bodyhood is met with in all bodies, but is not met with in lines and surfaces [the other genera of magnitude]" (Rescher, "Al-Kindi's Epistle on the Finitude of the Universe," p. 428). 
that in his epistle On The Finitude of The Universe, he remarks that by 'body' is meant "that which has length and breadth and depth."8 And here it should be noted that length, breadth, and depth fall under Aristotle's category of quantity; they are attributes of a primary substance, e.g., this body or this man. Moreover, in On First Philosophy, al-Kindi says that "a body has genus and species," and he compares bodies with "other objects which have quantity and quality."9 Genus and species, of course, are universals or secondary substances in Aristotle's sense, being predicated of a subject but not inhering in it. So, for example, in the sentence "John is a man", the species or universal 'man' is predicated of John, an individual man. 10

A second term requiring explanation here is 'magnitude', which appears in principles (5) and (6). Al-Kindi's use of this term indicates that magnitude is, first of all, a genus (i.e., a secondary substance), for it is said to be "(predicated) of body,"ll and is "met with in the line and the surface and the body," 12 since it is the single genus under which these various genera fall. Magnitudes are, furthermore, composed of parts and are therefore multiple. ${ }^{13}$ Moreover, the continuous magnitudes of body, area, line, place, and time "have dimensions and limits" in addition to being "divisible and separable."14

\section{III.}

Having laid out his six self-evident principles, al-Kindi next invites his reader to consider a body of infinite magnitude. A body, as a continuous magnitude, is necessarily separable into its parts, 15 and therefore the idea of a finite magnitude being subtracted or separated from it can be entertained. Now, according to al-Kindi, the body remaining after such a separation

8 Ibid.

9 Al-Kindi, "On First Philosophy," 114.8-10, p. 68.

10 See Aristotle, Categories, 2.a. $14 \mathrm{ff}$.

11 Al-Kindi, "On First Philosophy," 151.12, p. 102.

12 Rescher, "Al-Kindi's Epistle on the Finitude of the Universe," p. 428.

13 Al-Kindi, “On First Philosophy," 157.5, p. 109.

14 Ibid., 158.7, p. 110.

15 It is perhaps worth pointing out that none of the continuous magnitudes of body, area, line, place, or time is divisible in potentiality or actuality into another species. Thus, for example, a division of a body is body (157.10), and each section of a body "bears its definition and its name" (Ibid., 157.18, p. 109). 
will be either finite or infinite. But it cannot be finite. For if the finite (separated) body is added back to the remainder, the resulting body will be finite. Why so, exactly? Principle (5) states that when two bodies of finite magnitude are joined, the resulting body will also be finite in magnitude. In this case, however, the body formed from adding back the finite (separated) body to the remainder constitutes the same body from which the original separation was made - that is, the body of infinite magnitude. Thus, the resulting body is both finite and infinite in magnitude. And this contradicts principle (3) - the finite is not the infinite - which is just a substitution instance of $A$ is not non-A. So the body remaining after the separation of a finite magnitude cannot be finite.

Perhaps an example will be helpful in bringing al-Kindi's reasoning into clearer focus. Let $\mathbf{A B}$ be a body of infinite magnitude. Suppose, then, that $\mathbf{A}$, a body of finite magnitude, is separated from $\mathbf{A B}$. The resulting body $\mathrm{B}$ cannot be finite. For suppose that it were. Then, by principle (5), the addition of A (a finite body) to B (also a finite body) could only yield the finite body $\mathbf{A B}$. But this contradicts the original assumption that $\mathbf{A B}$ is a body of infinite magnitude. Hence, it is impossible that $\mathbf{B}$, the body resulting from the separation, be finite.

Is it possible, on the other hand, for $B$ to be infinite? It is not, says alKindi. For suppose that it were infinite. Then the finite (separated) body $A$, when added back to $\mathbf{B}$, would result in a body (AB)' such that either $(\mathbf{A B})^{\prime}$ would be greater than the original (infinite) body $\mathbf{A B}$ or $(\mathbf{A B})^{\prime}$ would be equal to body $\mathbf{A B}$. But the former alternative is clearly false, since if it were true that $(\mathbf{A B})^{\prime}>\mathbf{A B}$, then one infinite body would be greater than the other. By principle (6), therefore, the smaller infinite $\mathbf{A B}$ would be inferior to the greater infinite (AB) $)^{\prime}$ or to a portion of it. Thus, $\mathbf{A B}$ would be equal to a portion of $(\mathbf{A B})^{\prime}$. If so, however, then $A B$ would be finite; for it would be equal to a finite portion of (AB) ${ }^{\prime}$ and, according to principle (2), equal bodies possess limits whose dimensions are equal in actuality and potentiality. But this contradicts the original supposition that $\mathbf{A B}$ is a body of infinite magnitude; it is false, therefore, that $(\mathbf{A B})^{\prime}>\mathbf{A B}$.

But the second disjunct is also false, namely, that $(\mathbf{A B})^{\prime}=\mathbf{A B}$. Recall that the separation of finite body $A$ from an infinite magnitude $\mathbf{A B}$ is an initial assumption of the argument. It is further being supposed that the remaining body $B$ is infinite in magnitude, and that $(\mathbf{A B})^{-}$is the body resulting from the addition of $A$ (a finite body) and $B$ (an infinite body). To claim that $(\mathbf{A B})^{\circ}=\mathbf{A B}$, therefore, is to assert that a body can be added to 
another body without increasing it. But this is contradictory; for it implies that the whole (i.e., AB) ${ }^{\prime}$ is equal to one of its parts (i.e., B). 16

If sound, what al-Kindi's argument demonstrates is that no body of infinite magnitude can exist. For if there were a body of infinite magnitude, then if a body of finite magnitude were separated from it (and magnitudes are necessarily separable into their parts), then the remaining body would be either finite (alternative \#1) or infinite (alternative \#2). Both of these alternatives lead to contradiction. Therefore, it can be legitimately inferred that no body of infinite magnitude can exist.

\section{IV.}

Before proceeding with al-Kindi's argument further, it will be useful to pause and examine an objection to his reasoning arising from modern set theory. In arguing against alternative \#1, al-Kindi must suppose that the subtraction of a finite body from a body of infinite magnitude yields a finite remainder. This is a false supposition according to the deliverances of modern set theory. Axiomatic set theory states that an actually infinite magnitude comprises a set whose members are actually infinite in number.

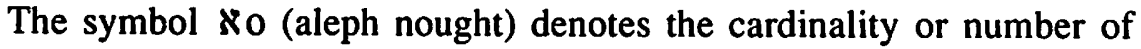
members of an actually infinite set. Now a peculiar property of infinite sets is that "one can add or subtract denumerably many members from [them] and not change the number of members in the set." 17 For any actually infinite set, therefore, $\aleph_{0}-n=\aleph_{0}$ and $\aleph_{0}+n=\aleph_{0}$ (where $n$ is any natural number). ${ }^{18}$ It is therefore a mistake to claim, as al-Kindi does in arguing against alternative \#2, that it is impossible to add to a bodily magnitude without increasing it. For this is to suppose that Euclid's Maxim - the whole is greater than its part - applies to infinite magnitudes; it does not. Concerning Euclid's Maxim, F.A. Shamsi comments:

16 Craig points out that al-Kindi refutes the second disjunct, not by appealing to principle (4), but rather by "utilising a principle that should have been added to his six: the whole is greater than [its] part" (Craig, Plato to Leibniz, p. 69). This principle, also known as Euclid's Maxim, can be derived directly from principles (2), (4), and (6), and indirectly from principle (1). See Ivry, "Commentary to 'On First Philosophy'," p. 150.

17 J.P. Moreland, Scaling the Secular City (Grand Rapids, MI: Baker Books, 1987), p. 21. 18 An interesting implication of these theorems is that "there is the same number of points in a one-inch line as there is in all of infinite space" (William Craig, The Kalam Cosmological Argument [London: Macmillan, 1979], p. 80). 
Insofar as finite magnitudes are concerned, the postulate is true of them - the (proper) part must necessarily be less in magnitude than the whole. But the postulate fails when infinite magnitudes are taken into consideration ... it is obvious that a finite subtraction from an infinite aggregation or magnitude cannot render that aggregation or magnitude finite. 19

Here Shamsi is exploiting a second unique property of an infinite set, namely, that it has a denumerable subset (where a set is denumerable just in case it can be put into a one-to-one correspondence with one of its proper subsets). Consider, for example, two infinite sets: 20 the set of all natural numbers $\{1,2,3, \ldots\}$ and the set of all even natural numbers $\{2,4,6, \ldots\}$. Since these two sets are actually infinite, the members of $\{1,2,3 \ldots\}$ can be placed in a one-to-one correspondence with the members of $\{2,4,6, \ldots\}$. Yet although the set of even natural numbers is a part of the set of natural numbers, they both have, according to infinite set theory, a cardinality of $\mathrm{No}$. Therefore, if the Principle of Correspondence validly applies to infinite sets, it follows that part of the set of natural numbers is equivalent to the whole set of natural numbers, a conclusion obviously at odds with Euclid's Maxim.

There is, therefore, a dilemma to be faced: If there were a body of infinite magnitude, then either the maxim that "the whole is greater than its parts" would apply to it or not. Now if the maxim applies, then al-Kindi's reasoning is vindicated, from which it follows that no infinite magnitude can exist. If, on the other hand, it does not apply (the Principle of Correspondence applying instead), then a body of infinite magnitude possibly exists, in which case al-Kindi's argument fails.

But is there any reason to think that the Principle of Correspondence is applicable to infinite magnitudes? The answer, I think, is that there is not. For if it were applicable, then it would be possible for metaphysically absurd states of affairs to obtain. Consider the following example due to alGhazali.21 Jupiter revolves once every twelve years, while the sphere of

19 Shamsi, "Al-Kindi's Epistle on What Cannot Be Infinite and of What Infinity May Be Attributed," p. 125

20 .The example is Craig's. See Craig, The Kalam Cosmological Argument, p. 73.

21 Al-Ghazali, Tahafut al-Falasifah [Incoherence of the Philosophers], trans. Sabih Ahmad Kamali (Lahore: Pakistan Philosophical Congress, 1958), p. 20. 
the fixed stars revolves every thirty-six thousand years. Now if the universe were eternal (and never began to exist), then according to infinite set theory the set of revolutions of Jupiter and the set of revolutions of the sphere of the fixed stars would be equal, the cardinality of both sets being $\mathrm{NO}$. But surely this is absurd. For the number of revolutions of Jupiter would be thousands of times greater than that of the sphere of the fixed stars if the universe were eternal. The application of the Principle of Correspondence to the existence of an actual infinite yields results which are metaphysically absurd. But, as Craig has pointed out, 22 necessarily, were an actually infinite magnitude to exist, then either the whole magnitude would be greater than any of its parts or it would not. (This is guaranteed by the Law of Excluded Middle.) In either case, however, there are attending absurdities; the proper course of action, therefore, would seem to be to deny the existence of infinite magnitudes. Thus, it seems to me that infinite set theory poses no insuperable obstacle to al-Kindi's argument.

\section{V.}

Al-Kindi next attempts to show that the universe is both spatially and temporally finite. It is a necessary truth that body falls under the genus of magnitude. Furthermore, any magnitude is necessarily separable into its parts. But, by definition, whatever is necessarily separable into its parts is quantitative. So body is necessarily quantitative. Moreover, if, as al-Kindi argues, it is impossible that a body of infinite magnitude should exist (see section III above), then letting ' $Q$ ' stand for "is quantitative", ' $I$ ' for "is infinite", and ' $b$ ' for "body", it follows that

$\sim 0(\mathrm{Qb} \& \mathrm{Ib})$

or alternatively,

$$
\square(\mathrm{Qb} \sim \mathrm{Ib}) \text {. }
$$

This may be granted. But how does al-Kindi propose to bridge the gap between ( 8 ) and the claim that the universe is temporally finite? Here he

22 See William Lane Craig, “Time and Infinity," International Philosophical Quarterly 31 (1991): 395. 
makes two closely related points. First, he points out that time is a continuous magnitude and is therefore divisible and separable into its parts. Thus, he says, time is necessarily quantitative. This is certainly correct. But does it follow that time is finite? As far as I can see, it does not unless, of course, it is also true that

$$
(\forall x) \square(Q x \supset \sim \mathrm{Ix})
$$

But the problem is that the inference from (8) to (9) is invalid. It has the form: $\square \mathrm{Fa} \rightarrow(\forall \mathrm{x}) \square \mathrm{Fx}$. And this modal principle has false instances. For example, if ' $a$ ' is "me" and ' $F$ ' is "is a person", then if ' $\square \mathrm{Fa} \rightarrow(\forall \mathrm{x}) \square$ Fx' is a correct modal principle, if I am essentially a person, everything is essentially a person, which is patently false.

The difficulty, then, is that from the fact that time is quantitative it follows that time is finite only if something like (9) is true. Unfortunately, al-Kindi never provides an argument for (9); he argues only for (8), which does not entail (9).

Secondly, al-Kindi points out that since an actually infinite body cannot exist, the body of the universe cannot be infinite. But, he says,

Things predicated of a finite object are also of necessity, finite. Every predicate of a body, whether quantity, place, motion or time ... and the sum of everything which is predicated of a body in actuality, is also finite, since the body is finite. 23

For al-Kindi, time is the duration of the body of the universe, and the body of the universe is finite; therefore, time is finite.

But the question at once arises: How can it be shown that time is the duration of the body of the universe? Al-Kindi's argument shows that the body of the universe is temporally finite only if body and time are necessary concomitants - only if, that is, $\square(B \equiv T)$. How is this to be proved? Well, since time is the "number of motion," 24 motion and time are necessary concomitants; it is impossible (by definition) that either motion or time occur without the other. Thus, $\square(\mathrm{M} \equiv \mathrm{T})$. If it could be established that

23 Al-Kindi, "On First Philosophy," 116.10 ff, p. 70, emphasis added.

24 Ibid., 117.5, p. 70. 
motion and body were necessary concomitants as well, it could easily be shown that $\square(B \equiv T)$. This is precisely what al-Kindi attempts to do. He first argues that motion can never exist without a body, that is, that $\sim \diamond$ ( $M$ $\& \sim B)$, or equivalently, $\square(M \supset B)$. Motion is a species of change, and change is always the change of some thing; for "change is a counting of the duration of the body." 25 It is therefore necessarily the case that if motion exists, body exists.

Al-Kindi goes on to argue that $\square(\mathrm{B} \supset \mathrm{M})$. Here two major arguments are advanced. Regarding the first, William Craig remarks that it is "poorly reasoned." 26 One is inclined to agree with him on this point. According to al-Kindi, body is necessarily such that if it exists, then either motion exists or motion does not exist. That is,

$$
\square[\mathrm{B} \supset(\mathrm{M} \vee \sim \mathrm{M})] \text {. }
$$

But it is obvious from sense perception that bodies exist. ${ }^{27}$ Hence,

$$
\square[(B \& M) \vee(B \& \sim M)] \text {. }
$$

The first disjunct in (11) is, of course, what Kindi wants to affirm, since it yields his desired result, namely, that the existence of body entails the existence of motion. What is required, then, is an argument for the denial of the second disjunct in (11).

Suppose for reductio, therefore, that $B \& \sim M$ is true; that is, that body exists but motion does not. Now $B \& \sim M$ entails $\sim M$, which, in conjunction with the logical truth $\sim \mathrm{M} \vee \diamond \mathrm{M}$, strictly implies

$$
\text { (12) } \quad(\sim \mathrm{M} \& \sim \nabla \mathrm{M}) \vee(\sim \mathrm{M} \& \diamond \mathrm{M}) \text {. }
$$

But to claim that motion does not exist, not even possibly so, is certainly contradictory, says Kindi. For the first disjunct of (12) tells us that motion does not exist. However, it is evident from sense-perception that bodies exist. However, since "body exists, motion is an existent."28 It follows,

25 Ibid., 117.12-13, pp. 70-71.

26 Craig, Plato to Leibniz, p. 117.

27 "... appeal to fact within a logical proof is typical of the type of argument al-Kindi uses" (Ivry, "Commentary to 'On First Philosophy'," p. 155).

${ }^{28}$ Al-Kindi, "On First Philosophy," 117.15, p.71. 
therefore, that $\sim \mathrm{M} \& \sim \diamond \mathrm{M}$ implies that motion exists and motion does not exist; thus, the first disjunct of (12) is necessarily false.

Unfortunately, there are two major defects in this proof. First, it appears that al-Kindi has begged the question at issue. It will be recalled that Kindi has already shown that $\square(\mathrm{M} \supset \mathrm{B})$. Now he is in the midst of a proof that will establish that $\square(B \supset M)$, his ultimate goal being to show that body and motion are necessary concomitants. Thus, Kindi cannot assume $B \supset M$ in order to argue against the first disjunct of (12). This is question-begging, since (12) is itself a premise in the argument being advanced in support of the truth of $\square(B \supset M)$.

Secondly, the inference of (11) from (10) and the proposition bodies exist is modally invalid; for bodies exist is only contingently (and not necessarily) true. If it were necessarily true, then the universe would be eternal, a conclusion obviously at odds with al-Kindi's philosophy. And if it were only contingently true that bodies exist, then it would follow that (B \& $M) \vee(B \& \sim M)$ was only contingently true as well. This is somewhat problematic. For then even if al-Kindi were able to show that $B \& \sim M$ was necessarily false, he would only be able to conclude that B \& $M$ was contingently true. But then $B \supset M$ could only be contingently true, leaving open the possibility that $B \& \sim M$. Thus, even if motion and time were necessary concomitants, it would still be possible that body and time were not. On this scenario, then, even if it were impossible for the universe to be spatially finite, it would still be possible for it to be temporally infinite. Though not devastating to al-Kindi's argument, this finding does contradict his claim that motion and body are necessary concomitants.

In any event, al-Kindi goes on with a refutation of the second disjunct of (12). That disjunct says that as a matter of fact motion does not exist, but nevertheless that it is possible that it does exist in some body. In order to show that $\sim \mathrm{M} \& \diamond \mathrm{M}$ is contradictory, Al-Kindi now reasons that if a body exists and motion possibly exists in some body, then "motion necessarily exists in some bodies." 29 But why so? "That which is possible," he contends, "is that which [actually] exists in some possessors of its substance."30 Thus, for example, the art of writing is a possibility (though not an actuality) for the Prophet because it (does) exist in some other man. In commenting on this passage, Ivry points out that al-Kindi accepts "the priority of actuality

29 Ibid., 118.4, p. 71.

30 Ibid. 
to potentiality," 31 and therefore that something is possible only if it is actualized in some other member of the species. Indeed, later in On First Philosophy, al-Kindi remarks,

\begin{abstract}
Everything which belongs potentially to something can be brought to actuality only by another thing. That which brings something from potentiality to actuality is itself in actuality. 32
\end{abstract}

To be sure, if the possibility of motion exists in some body, then in order for that possibility to be actualized, something must bring it to actuality. In this sense, actuality is prior to potentiality. But it does not follow from what al-Kindi has said here that a thing is possibly in motion only if some other member of the same species is actually in motion.

Again, the difficulty here is a modal one. From B \& $\diamond \mathrm{M}$ it follows that $\diamond \mathrm{M}$, that is, that motion possibly exists in some body. Should we conclude from this (along with al-Kindi) that motion necessarily exists in some body? Surely not. What follows from $\diamond \mathrm{M}$ is not $\square \mathrm{M}$, but only $\square \diamond \mathrm{M}, 33$ that is, that the possibility of motion necessarily exists in some body or another. But $\square \diamond \mathrm{M}$ does not entail $\mathrm{M}$, which it must if al-Kindi's argument is to go through.

Al-Kindi's conclusion, nonetheless, is that since motion possibly exists in some body, it actually exists in some body. However, from the second disjunct of (12) - that is, from $\sim \mathrm{M} \& \diamond \mathrm{M}$ - it can be deduced that motion does not exist. And since, for al-Kindi, $\diamond \mathrm{M}$ entails $\square \mathrm{M}$ (and so $\mathrm{M}$ ), it can also be deduced that motion does exist. Hence, $\sim \mathrm{M} \& \diamond \mathrm{M}$ implies that motion exists and motion does not exist. This is flatly contradictory; thus, the second disjunct of (12) is also necessarily false. Now since both disjuncts of (12) are necessarily false, it follows that (12) is as well. But recall that (12) is entailed by (B \& $\sim \mathrm{M})$ and $(\sim \vee \mathrm{M} \vee \diamond \mathrm{M})$. Therefore, if (12) is necessarily false, then either $(B \& \sim M)$ or $(\sim \diamond \mathrm{M} \vee \diamond \mathrm{M})$ is also necessarily false. Since $\sim \diamond \mathrm{M} \vee \diamond \mathrm{M}$ is an instance of the Law of Excluded Middle, it follows that

31 Ivry, "Commentary to 'On First Philosophy'," p. 155.

32 Al-Kindi, “On First Philosophy," 155.3-5, p. 106.

33 The inference from $\diamond \mathrm{p}$ to $\square \diamond \mathrm{p}$ is the characteristic formula of the S5 system of modal logic. S5 has commended itself to most philosophers of logic as the system that best captures our notions of possibility, impossibility, and necessity. The inference from $\diamond_{p}$ to $\square p$ is invalid in Feyes' system T and the Lewis systems S4 and S5. See Kenneth Konyndyk, Introductory Modal Logic (Notre Dame: University of Notre Dame Press, 1986), pp. 31-55. 
(13) $\square \sim(B \& \sim M)$.

And (11) and (13) jointly entail

$$
\square(\mathrm{B} \supset \mathrm{M})
$$

which is what al-Kindi set out to prove.

The second major argument advanced for the conclusion that body cannot exist without motion is couched in an objection entertained by alKindi. Perhaps the body of the universe was originally at rest (from eternity) and then, since it had the possibility of motion, subsequently began to move. If sound, this objection would undercut creatio ex nihilo; for the body of the universe would then be eternal and would never have begun to exist. 34 Suppose that this is indeed the case, says al-Kindi; that is, suppose the universe was eternally at rest but then subsequently moved. Then the body of the universe would either have been generated from nothing or it would be eternal. If the former alternative is true, then the very generation of the body of the universe would be a motion, since generation is a species of motion. ${ }^{35}$ Accordingly, at no time $t$ would the body of the universe be found to be existing without motion; hence, it would not be the case that body precedes motion. By hypothesis, however, body does precede motion. Hence, body both precedes and does not precede motion. Consequently, even if the body of the universe were generated from nothing, body would not precede motion.

There is, I think, one serious problem with this argument; it assumes that the generation of the body of the universe is a motion, a species of change. But is this really the case? I do not think so. To begin with, change is always change from a prior state to a later state; al-Kindi has already established that motion (change) and time are necessary concomitants, so that motion (change) entails the existence of temporally prior states. Furthermore, change is always the change (over time) of some thing. This is evident from al-Kindi's observation that if motion exists, body exists.

34 This would not, however, "exclude the possibility that there exists a personal being who initiates the temporal series of events into a quiescent universe" (William Craig, "The Kalam Cosmological Argument and the Hypothesis of a Quiescent Universe," Faith and Philosophy 8 [1991]: 106). A recent proponent of the objection al-Kindi entertains is Stewart Goetz. See his "Craig's Kalam Cosmological Argument," Faith and Philosophy 6 (1989): 99-102. 35 Al-Kindi, “On First Philosophy," p. 71. 
Now the creation (generation) of the body of the universe out of nothing implies two things: (i) there is no time prior to creation, ${ }^{36}$ and (ii) no bodies exist prior to creation. But if, as al-Kindi claims, the generation of the body of the universe is a motion or change, then there is (of necessity) both time and body prior to creation. Thus, al-Kindi's argument here is doubly contradictory; it is false, therefore, that the generation of the body of the universe is a motion.

Regarding the second alternative, namely, the supposition that the body of the universe is eternal, al-Kindi contends that if this were the case and the body of the universe were to subsequently move (because it had the possibility of motion), then it would be a movement from a state of actual rest to a state of actual motion. This is a change. ${ }^{37}$ But the eternal cannot change; change is a movement from deficiency to perfection, but the eternal is necessarily perfect, and that which is perfect exists in a fully actual state "whereby it excels." 38 Accordingly, the eternal does not move. But, by hypothesis, the body of the universe is eternal and does move. The eternal, therefore, both moves and does not move. Again, this is contradictory. Hence, it follows that body cannot exist without motion.

The upshot of all this is that al-Kindi has provided two major arguments for the conclusion that it is necessary that if body exists, motion exists. As mentioned earlier, this is a critical premise in his overall argument. Having established that $\square(M \supset B)$ and now that $\square(B \supset M)$, al-Kindi can justifiably assert that $\square(B \equiv M)$, that body and motion are necessary concomitants. Now given that motion and time are also necessary concomitants, it follows logically and inescapably that body and time are necessary concomitants: $\square(B \equiv T)$. Recall that al-Kindi's proof for creation began with an argument for the finitude of the body of the universe. Furthermore, the claim was made that time is the duration of the body of the universe, and therefore that if the body of the universe is finite, time is finite as well. It was noted that this would be true only if body and time were necessary concomitants. The proof for this claim (defective though it may be) is now in. Al-Kindi therefore concludes that since (i) the body of the universe is finite, (ii) time

36 William Craig offers the following definition of a thing's beginning to exist: " $x$ begins to exist' = def. ' $x$ exists at $t$ and there is no time immediately prior to $t$ at which $x$ exists'." See William Lane Craig, "The Origin and Creation of the Universe: A Reply to Adolph Grinbaum," British Journal for the Philosophy of Science 43 (1992): 238.

37 Al-Kindi, "On First Philosophy," 114.1 ff, pp. 67-68.

38 Ibid., 114.6-7, p. 68. 
is the duration of the body of the universe, and (iii) body and time are necessary concomitants, the body of the universe is spatially and temporally finite. In other words, the universe is not eternal; it began to exist a finite time ago.

\section{VI.}

Even so, it does not immediately follow that the body of the universe is created. After all, perhaps the need for a Creator of the universe can be averted by holding that the universe is self-caused. In order to eliminate this possibility, Al-Kindi posits the following logically exhaustive disjunction:

For any thing $\mathrm{T}$ and its essence $\mathrm{E}$ either

(a) $\sim$ (T exists) \& $\sim$ (E exists)

or

(b) $\quad \sim$ (T exists) \& E exists

or

(c) $\quad T$ exists \& $\sim($ E exists)

or

(d) T exists \& E exists.

Now the question at hand is: Can a thing "be the cause of the generation of its essence," 39 that is, the cause of "its becoming a being, either from something or nothing?" 40 Clearly, since al-Kindi understands the "essence of every thing [to be] that thing," 41 we should see him as inquiring whether a thing can bring itself into existence. The answer, al-Kindi affirms, is that it cannot. For consider each of the alternatives (13 a-d). If (13a) were true, then in order for a thing to be the cause of its existence it would have to exist (since ex nihil, nihil fit). ${ }^{42}$ But (13a) says that the thing in question

39 Al-Kindi, “On First Philosophy," 123.5, p. 76.

40 Ibid.

41 Ibid., 124.12, p. 77.

42 One contemporary philosopher who has not shied away from affirming that being can arise uncaused out of absolute nothingness is Quentin Smith. According to Smith, "the most reasonable belief is that we came from nothing, by nothing and for nothing" (William Lane Craig and Quentin Smith, Theism, Atheism, and Big Bang Cosmology [Oxford: Clarendon Press, 1993], p. 135). 
does not exist. So it exists and it does not exist. It would therefore be impossible for a thing to be the cause of its own existence if (13a) were true. Similarly, then, for (13b). This alternative states that the thing does not exist but its essence does. This is contradictory; the essence of a thing is that thing. So if the thing did not exist, then it could not be the cause of its existence (since out of nothing, nothing comes). (13c) fails for precisely the same reasons. The last alternative to be considered is (13d). If (13d) were true, then a thing would have to be the cause of its essence, the essence being an effect following from the thing. But this is absurd; a thing and its essence are the same thing, whereas a cause and its effect are distinct. Consequently, if (13d) were true, a thing could not be the cause of its own existence.

There are only four alternatives with respect to the relationship between a thing and its essence. Under each of these scenarios, however, it turns out that it is impossible for a thing to be the cause of its existence. Al-Kindi's conclusion on this point is, I think, quite correct:

(14) It is impossible that anything be the cause of its own existence.

And from (14) it follows quite appropriately that

(15) It is impossible that the body of the universe be the cause of its own existence.

The inference to creation and, therefore, to a Creator is close at hand. Given that the universe began to exist in the finite past, there seem to be three alternatives with regard to its coming to have existed. Either it came to be out of nothing (which is absurd), or it caused itself to exist (which has also been shown to be absurd), or it was created. Since the first two alternatives are impossible, the inference to the universe's being created by a Creator (i.e., God) seems entirely justified.

\section{VII.}

By way of conclusion, then, it is clear that al-Kindi's philosophical doctrine of creation depends on his arguments for the body of the universe beginning to exist at some point in the finite past. Starting from six self- 
evident principles, al-Kindi is able to show (successfully, I think) that no body of actually infinite magnitude can exist, and thus that the body of the universe cannot be infinite. But his claim that the universe is, in addition, temporally finite, given that time is the duration of the body of the universe, was seen to follow only if body and time are necessary concomitants. The crucial premise required to prove this was that body cannot exist without motion. Unfortunately, the two supporting arguments for this premise were found to be flawed in various respects. It seems to me, therefore, that alKindi's argument for the necessary concomitance of body and time, and therefore the inference to the temporal finitude of the universe (and ultimately its creation by God), is not justified. This is not to say, however, that al-Kindi has failed altogether to show that the universe began to exist at some point in the finite past. For he has at his disposal two other arguments for this conclusion: an argument from composition and an argument based on the impossibility of traversing an actual infinite; both of these seem very promising. Moreover, there is no reason to think that the argument based on body, motion, and time could not be revised so as to provide us with the desired conclusion. The door has not been shut on the Kindian arguments for the creation of the universe and the existence of a Creator; al-Kindi's efforts in this regard certainly warrant the critical attention of contemporary philosophers interested in these and related matters.

\section{BIBLIOGRAPHY}

Atiyeh, George. Al-Kindi: The Philosopher of the Arabs. Rawalpindi: Islamic Research Institute, 1966.

Craig, William L. The Kalam Cosmological Argument. London: Macmillan, 1979.

- The Existence of God and the Beginning of the Universe. San Bernardino, CA: Here's Life Publishers, Inc., 1979.

- The Cosmological Argument from Plato to Leibniz. London: Macmillan, 1980.

- "The Kalam Cosmological Argument and the Hypothesis of a Quiescent Universe." Faith and Philosophy 8 (1991): 104-108.

—. "The Origin and Creation of the Universe: A Reply to Adolf Grünbaum." British Journal for the Philosophy of Science 43 (1992): 233-240.

Davidson, Herbert A. "John Philoponus as a Source of Medieval Islamic and Jewish Proofs of Creation." Journal of the American Oriental Society 89 (1969): 359361. 
El-Ehwany, Ahmed Fouad. "Al-Kindi." In A History of Muslim Philosophy. ed. M.M. Sharif. Wiesbaden: Otto Harrassowitz, 1963.

Fakhry, Majid. "The Classical Islamic Arguments for the Existence of God." Muslim World 47 (1957): 140.

- A History of Islamic Philosophy. 2nd ed. New York: Columbia University Press, 1983.

Al-Ghazali. Tahafut al-Falasifah [Incoherence of the Philosophers]. Translated by Sabih Ahmad Kamali. Lahore: Pakistan Philosophical Congress, 1958.

Goetz, Stewart C. "Craig's Kalam Cosmological Argument." Faith and Philosophy 6 (1989): 99-102.

Ivry, Alfred L. "Al-Kindi as Philosopher: The Aristotelian and Neoplatonic

Dimensions." In Islamic Philosophy and the Classical Tradition. eds. S.M. Stern, Albert Hourani, and Vivian Brown. Columbia, S.C.: University of South Carolina Press, 1972.

—. "Commentary on 'On First Philosophy'." In Al-Kindi's Metaphysics: A Translation of Ya 'qub ibn Ishaq al-Kindi's Treatise 'On First Philosophy'. Albany, N.Y.: State University of New York Press, 1974.

Konyndyk, Kenneth. Introductory Modal Logic. Notre Dame, IN: University of Notre Dame Press, 1986.

Moreland, J.P. and Kai Neilson. Does God Exist: The Great Debate. Nashville, TN: Thomas Nelson, Inc., 1990.

Moreland, J.P. Scaling the Secular City. Grand Rapids, MI: Baker Books, 1987.

Oppy, Graham. "Craig, Mackie, and the Kalam Cosmological Argument." Religious Studies 27 (1992): 189-197.

Rescher, N. and H. Khatchadourian. "Al-Kindi's Epistle on the Finitude of Universe." Isis 57 (1966): 426-433.

Shamsi, F.A. "Al-Kindi's Epistle on What Cannot Be Infinite and of What Infinity May Be Attributed." Islamic Studies 14 (1975): 123-144.

Smith, Quentin. "Atheism, Theism, and Big Bang Cosmology." Australasian Journal of Philosophy 69 (1991): 48-66.

—. "A Big Bang Cosmological Argument for God's Non-Existence." Faith and Philosophy 9 (1992): 218-228.

Staley, Kevin. "Al-Kindi on Creation." Journal of the History of Ideas 50 (1989): 355-370.

Walzer, Richard. "Islamic Philosophy." In History of Philosophy, Eastern and Western. 2 vols. ed. S. Radhakrishnan. London: Allen \& Unwin, 1953.

—. "New Studies on Al-Kindi." In Richard Walzer, Greek into Arabic: Essays on Islamic Philosophy, Oriental Studies. Oxford: Bruno Cassier, 1962.

Ya'qub ibn Ishaq al-Kindi. Al-Kindi's Metaphysics: A Translation of Ya 'qub ibn Ishaq al-Kindi's Treatise on 'First Philosophy'. Translated with an Introduction and Commentary by Alfred L. Ivry. Albany, N.Y.: State University of New York Press, 1974. 